\title{
OKT3-Induced Sterile Peritonitis: Report of a Case
}

\begin{tabular}{|l|l|l|}
\hline O.F. & Oliver F. & Bathe \\
\hline L.C. & Leendert C. & Paul \\
\hline
\end{tabular}

\section{Department of Medicine, Foothills Hospital and University of Calgary, Alberta, Canada} L.C. Paul, Division of Nephrology, Foothills Hospital, 1403-29th Street N.W. Calgary, Alberta T2N 2T9 (Canada)

\section{Dear Sir,}

The use of OKT3 monoclonal antibodies to treat acute renal transplant rejection is frequently accompanied by a constellation of side effects [1,2]. About 50$80 \%$ of patients experience some combination of fever, chills, dyspnea, wheezing, tachycardia, hypotension, nausea and vomiting within hours following the 1 st or 2nd dose [2]. Two to five days after initiation of therapy, symptoms of gastrointestinal and nervous system irritability may predominate fl] with frank aseptic meningitis between 3 and 14\% of cases [2-4]. We observed a case of sterile peritonitis in association with OKT3 therapy and postulated a causal relationship.

A 58-year-old male with end-stage renal disease of unknown etiology received a cadaveric renal transplant in 1989. He had been on chronic ambulatory peritoneal dialysis (CAPD) since 1987 and had experienced two episodes of bacterial peritonitis. A specimen of CAPD fluid taken immediately before transplantation contained no polymorphonu-clear granulocytes or microorganisms. Post-transplant immunosuppression consisted of prednisone and ciclosporin and the transplant functioned immediately. On the 10th post-transplant day, serum creatinine started to rise and antirejection treatment with Solu-Medrol was instituted. A Finney ureter catheter was removed on day 12 and a 4-day course of Norfloxacin was started prophylac-tically. Because of a further rise in serum creatinine, OKT3 therapy in a dose of $5 \mathrm{mg}$ / day was started on day 17. No immediate reaction to the treatment was noted but the next morning the patient complained of generalized weakness. Because of declining graft function, CAPD was reinstituted and it was noted that the effluent was cloudy. The next day, the CAPD effluent continued to be cloudy and repeated gram stainings of the dialysate revealed numerous polymorphonu-clear granulocytes, but no microorganisms while repeated cultures remained sterile. Antibiotic therapy with vancomycin and to-bramycin was nevertheless instituted per CAPD catheter and the effluent became clear within 12 h; daily OKT3 therapy was continued for 10 days. Plasma creatinine, which had risen to $861 \mu \mathrm{mol} / \mathrm{l}$ on the 2nd day of OKT 3 administration, declined to $225 \mu \mathrm{mol} / 1$ at discharge.

Based on the temporal relationship between the administration of OKT3 and the diagnosis of sterile peritonitis, we postulated a causal relationship. It is, however, difficult to exclude that the patient had developed asymptomatic bacterial peritonitis in the early post-transplant days which had been treated with the Norflaxacin that was prescribed for other reasons. Furthermore, up to one third of cases of peritonitis are culture negative [5]. The post-transplant episode of increased leukocyte counts in the peritoneal fluid was, however, clinically extremely mild and coincided with an increase in the peripheral white blood cell count. We hypothesize that the cytokine and inflammatory mediators released following OKT3 therapy [6] that cause leukocyte accumulation in the cerebrospinal fluid may also produce influx of leukocytes into other compartments such as the peritoneal cavity. Such increases in the intraperito-neal leukocyte count are very likely clinically asymptomatic and only detected when CAPD exchanges are instituted.

References

Todd PA, Brogden RN: Muromonab CD3: A review of its pharmacology and therapeutic potential. Drugs 1989;37:871-899.

Thistlethwaite Jr JR, Stuart JK, Mayes JT, Gaber AO, Woodle S, Buckingham MR, Stuart FP: Monitoring and complications of monoclonal therapy: Complications and monitoring of OKT3 therapy. Am J Kidney Dis 1988; 11:112-119.

Martin MA Massanari RM, Nghiem DD, Smith JL, Corry RJ: Nosocomial aseptic meningitis associated with administration of OKT3. JAMA 1988;259:20022005.

Rizzo JD, Rowe S A: Meningism in a ten-month-old infant during OKT3 therapy. J Heart Transplant 1990;9:727-728.

Males BM, Walshe JJ, Amsterdam D: Laboratory indices of clinical peritonitis: Total leukocyte count, microscopy and microbiologic culture of peritoneal dialysis effluent. J Clin Micro-biol 1987;25:2367-2371.

Gaston RS, Deierhoi MH, Patterson T, Prast-hofer E, Julian BA, Barber H, Laskow DA, Diethelm AG, Curtis JJ: OKT3 first-dose reaction: Association with T cell subsets and cytokine release. Kidney Int 1991 ;39:141-148.

(C) 1992 S.KargerAG, Basel 0028-2766/92/ 0621-0117S2.75/0 